\title{
AN ANALYSIS OF SMART FARMERS' PERCEPTIONS TOWARDS THE ASEAN ECONOMIC COMMUNITY
}

\author{
YI-CHIA LIN ${ }^{1}$, DARUNEE YOTIMART ${ }^{2}$, ANUPONG WONGCHAI $^{3} \&$ CHALERMPON JATUPORN $^{4}$ \\ ${ }^{1}$ Institute of Public Affairs Management, National Sun Yat-sen University, Taiwan \\ ${ }^{2}$ Humanities and Sociology, Payap University, Thailand \\ ${ }^{3}$ Department of Agricultural Economy and Development, Chiang Mai University, Thailand \\ ${ }^{4}$ School of Economics, Sukhothai Thammathirat Open University, Thailand
}

\begin{abstract}
The establishment of the ASEAN Economic Community (AEC) is a major milestone for Southeast Asia. This establishment offers enormous opportunities, in terms of regional labour markets and economic integration of a market with a large value of about US\$2.6 trillion and over 622 million people. This research aims to study the characteristics of the "smart farmers" in the upper northern provinces of Thailand and to analyse their perceptions towards the AEC. The study's primary data were randomly collected from 400 questionnaires given out in nine provinces. The main research method was the logit model with maximum-likelihood estimation (MLE) that was theoretically applied. The results revealed that most responders were male (89\%), 51-60 years old (62\%), with a Grade 4 elementary school level $(58 \%)$. The percentage of the sample who owned less than ten rai (approximately 40 acres) and earned 100,001-250,000 Thai baht as income per year was $46 \%$ and $30 \%$, respectively. The study found that the factors of their participation in seminars about agriculture and their knowledge enquiry had influenced their perceptions and awareness of the AEC (with a 95\% reliability score). Furthermore, their follow-up of marketing news was positively related to the potential of their perceptions and awareness of the AEC (with a $99 \%$ reliability score). The forecasting accuracy formula was more accurate than $88 \%$. This research suggested that knowledge about the AEC should be distributed, especially to the agricultural village leaders and farmers, through the media of wire broadcasting and knowledge-sharing meetings in each village. Moreover, development of innovations to help enhance their knowledge about the AEC should be increased.
\end{abstract}

Keywords: agriculture, ASEAN Economic Community, news, perceptions, smart farmers, Thailand, upper northern provinces.

\section{INTRODUCTION}

The ASEAN Economic Community (AEC) was launched by the leaders of the Association of South East Asian Nations (ASEAN) in 2003, with the aim to set up an integration plan covering all aspects of its ASEAN member states' economics. The international organization was officially established in 2015, so the ASEAN countries could become a single market, a production-based economy, as well as to put emphasis on developing global economic equality. This organization consists of ten member countries that are mostly agriculturalproducing countries: Thailand, Indonesia, Malaysia, Singapore, Philippines, Brunei, Vietnam, Myanmar, and Cambodia. The free trade in agriculture had begun in 2010, by setting up that agricultural products of six countries (Thailand, Singapore, Philippines, Indonesia, Brunei, and Malaysia) have zero percent tax rates, except!for those in sensitive lists that must be reduced, which were set as unable to go over five percent. Also, the four ASEAN member countries of Vietnam, Laos, Myanmar, and Cambodia have an agreement to reduce their taxes to zero in the near future [1].

Being in the ASEAN Economic Community has both positive and negative effects on Thailand's agriculture. First, the positive impacts are increased exporting of agricultural products and food, due to the reduction in their taxes. Moreover, since ASEAN is the agricultural export market that includes cheap imported materials, production costs are 
reduced. The negative impacts are, for instance, that some agricultural fields might get some effects from the lowering of prices, because of importing inexpensive goods from the ASEAN member countries. Agricultural industries having low efficiency in production cannot compete with other countries. The flow of Thai skilled labour to other countries could cause Thailand to lack agricultural laborers [2].

Consequently, all associated individuals need to realize and truly understand more about the ASEAN Economic Community, to enhance their production and the competition potential of Thailand. According to the findings of many institutions, such as the Center for International Trade Studies of the University of the Thai Chamber of Commerce: this study found that $100 \%$ of Thai farmers still do not understand what the AEC is, and that $90 \%$ of the population had little knowledge and understanding about the AEC [3]. From this fact, the establishment of an understanding in farmers is needed, by helping give them access to the key factors that can lead them to prepare and develop themselves. Thus, the researchers conducted an analysis of the factors influencing Thai farmers' perceptions and awareness, so that the study results would be beneficial for planning, developing and relating the potential of the farmers to effect agriculture changes for the AEC. This study is also hoped to be helpful for the Office of Agricultural Economics, as the organization planning and setting up the policies of Thailand's Ministry of Agriculture and Cooperatives, including all divisions within the province that are the responsibility of the 1st Office of Agriculture Economics, in Chiang Mai, Thailand, so it can use the findings for further benefit.

$$
\begin{aligned}
& \text { Individual factors } \\
& \cdot \quad\left(X_{1}\right) \text { gender } \\
& \cdot \quad\left(X_{2}\right) \text { age } \\
& \left(X_{3}\right) \text { educational level }
\end{aligned}
$$

\section{Economic factors}

$\left(X_{4}\right)$ size of agricultural land area owned $\left(X_{5}\right)$ income

\section{$\underline{\text { Social factors }}$}

. $\left(X_{6}\right)$ participation in meetings/agricultural training

- $\left(X_{7}\right)$ participation in agricultural fairs/exhibitions

- $\left(X_{8}\right)$ agricultural knowledge acquisition from many sources

. $\left(X_{9}\right)$ information access

- $\left(X_{10}\right)$ fondness and pride in cultivation

. $\left(X_{11}\right)$ gathering or being the member of cooperatives

Figure 1: Research framework. 
Kanokon et al. [4] explained that Thai farmers' perceptions and awareness of the AEC, particularly the level of perception and awareness about investment, labour and standards for certification; and of approval of fund establishment, which was used for structural production adjustments to increase more potential competition, was low to quite low. Mostly, they receive knowledge from village leaders or communities; and they receive information through media, especially from television.

Corry et al. [5] study information-receiving behaviours, knowledge, attitude, trends in behaviours towards the perception and awareness of the AEC. They also investigated the population's characteristics which influence their perceptions and awareness of the AEC. Most respondents received their information through news about the AEC, from televisions. This study suggested that the population's characteristics must be considered!carefully. Moreover, that media production must be done relevantly with respect to their target, as much as it can be.

\section{LITERATURE REVIEW}

\subsection{Theories of perceptions and awareness}

Perceptions are a mental process which is quite complex, and its interpretation is done by the senses, by using knowledge or obtaining knowledge to help interpret a meaning. Also, if it is considered in terms of a behaviour, perception is a process occurring between a stimulation and response, so this becomes an important thing for learning perception is a way leading to understanding the interpretation of meaning.

The idea of perceptions in this study is that perception is a process used to assess and interpret the meanings of various kinds of data around us, after we are internally and externally stimulated and have interpreted it in the form of an idea, knowledge, understanding and action. Nazir and Liljenström [6] explain that news is the main factor used for human decision-making. Information will be more needed when people want to use it for making a decision, or when they are not sure about something; however, if they don't receive all the information, but rather choose to receive some information that they think is useful for them.

Stimulations leading any individuals to receive information depend on the basic qualifications of their receivers, as follows:

1. Mental components, such as the process of choosing information based on the receiver's attitude and experience.

2. Social or environmental components, such as family, culture, tradition, and characteristics of the population like age, gender, background, education and social status.

Zhang et al. [7] also opined that an individual receives information from mass media for these following four needs:

1. The need for surveillance, by following movements and observing surroundings from mass media, so that the searchers can catch up with all events and situations and know what must be known.

2. They need to make a decision, particularly a decision related to their daily lives, so that receiving information makes them be able to give opinions on any circumstances or surrounding situations.

3. They need a discussion, since receiving information from mass media allows them to use the information received in discussions with others. 
4. They need participation, by being aware and participating in any situations that are happening in a society.

2.2 Theories associated with the study of behaviours, as follows;

Zahedzadeh [8] found there were two types of behaviours, classified as follows:

1. Overt behaviours or external behaviours, which are behaviours that we can see coming from actions; and

2. Covert behaviours or internal behaviours, such as are in an individual's internal awareness, but that these can be measured from external behaviours. For example: feelings, thoughts, emotions, perceptions, decisions, attitudes and needs are behaviours that cannot be observed, except when they are measured by an instrument.

Kykalová and Vasilyeva [9] also explained that there are three methods of behaviours, as follows:

1. Perception is the process that receives information from environmental states, which are perceived through the senses, including a sensation.

2. Cognition is the mentally- associated process that includes learning, memorizing and thinking. The metal processes also include the development of the learning process, as well as the intellectual process. This perception causes an emotional response and affect, which are internal behaviours.

3. Spatial behaviour is the process where an individual has some behaviours associated with some circumstances, and these behaviours are overt behaviours that can be observed.

Hüseyin [10] explained the importance of awareness as follows;

1. Awareness is important for learning; it can be observed from the process shown in Fig. 2.

2. Awareness is important for attitude, emotion, and behavioural trends.

Whenever awareness occurs, feelings and emotions develop, and they will become attitudes and then behaviours.

\section{METHODOLOGY}

We aimed to study the factors that affect the Thai "smart farmers" perceptions and awareness of the ASEAN Economic Community. We used the upper northern areas in Thailand as the research area. Our sample size included 122 samples, questionnaires. The variables used in

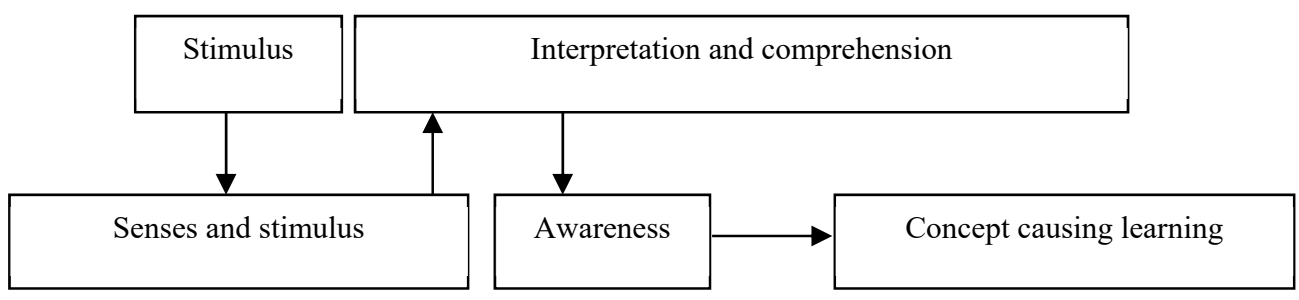

Figure 2: Process of awareness. 
this study were two variables: independent variables and dependent variables. The dependent variables were the smart farmers' perceptions and awareness of the AEC. They were classified into three factors, as follows:

1. Individual factors!
a. Gender
b. Age
c. Education level

2. Economic factors!

a. Size of the agricultural areas

b. Incomes (agricultural incomes)

3. Social factors

a. Participation in agricultural meetings/training sessions

b. Participation in agricultural fairs/exhibitions

c. Agricultural knowledge acquisition from many sources, such as: televisions, radios, newspapers, and the Internet

d. Information access such as training sessions and organization access

e. Fondness and pride in farming

f. Gatherings or being the member of cooperatives

g. Having roles in the group or in the cooperatives

h. Following marketing news!

The data used for this study are secondary data which were collected from the 1st Office of Agricultural Economics, Chiang Mai, Thailand, which takes care of the areas covering six provinces, namely Chiang Rai, Chiang Mai, Phayao, Lamphun, Lampang, and Mae Hong Son. Stratified random sampling and simple random sampling without replacement were used in this research. The data were mainly information from related government sectors, such as the Office of Agricultural Economics, Department of Agricultural Extension, including the data from previous research and publications.

The researchers analysed the factors influencing the "smart farmers" perceptions and awareness by using the logit model, as the variables used in the study were probabilities that have values between 0 and 1 , where:

$$
y_{i}^{*}=x_{i}^{*} \beta+u_{i} .
$$

Wongchai [11] indicated that for $y_{i}^{*}=$ the value that cannot be observed called a latent variable representing the "smart farmers" perceptions and awareness. If the values of the "smart farmers" perceptions and awareness are more different $\left(y_{i}^{*}>0\right)$, then the value $y_{i}=0$.!

$y_{i}=1$ if $y_{i}^{*}>0$ indicates that the smart farmers were aware of the AEC.

$y_{i}=0$ if $y_{i}^{*} \leq 0$ indicates that the smart farmers were not aware of the AEC.

These criteria determined the "smart farmers" perceptions and awareness of the AEC: more than $80 \%$ of "smart farmers" having knowledge about the AEC, was considered as them being aware of the AEC.

Less than $80 \%$ of the "smart farmers" lacking knowledge about the AEC, was considered as the farmers not being aware of the AEC.

The cumulative distribution function for logistic variables is as seen in eqn (2): 


$$
F(l)=p[L \leq 1]=\frac{1}{1+e^{-1}}
$$

\section{RESEARCH FINDINGS}

According to the findings of this study examining the factors influencing "smart farmer" perceptions and awareness of the AEC, 49 "smart farmers" (40.2\%) were found to have knowledge about the AEC; while 73 "smart farmers" (59.8\%) had no knowledge about the AEC. In terms of gender, $34.4 \%$ of the "smart farmers" who had knowledge about the AEC were male, while $5.8 \%$ of them were female. The study found that $45.1 \%$ of the "smart farmers" who had no knowledge about the AEC were male, while $14.7 \%$ of them were female. In terms of gender, $20.5 \%$ of the "smart farmers" around 51 to 60 years of age had knowledge about the AEC; while $29.5 \%$ of the "smart farmers" aged around 51 to 60 had no knowledge about it. Also, as most of the "smart farmers" received a compulsory education, which is at least a Grade 4 elementary school level, most of them had little awareness.

The sample group owned the average agricultural areas at 14 rai, and most of them had areas with fewer than 10 rai $(45.9 \%)$. Similarly, $30.3 \%$ of the smart farmers had agricultural areas with fewer than 10 rai. In terms of income, most of them $(29.5 \%)$ earned between 100,001 and 250,000 Thai baht per year. Our results showed that $13.9 \%$ of the smart farmers knowing about the AEC earned between 100,001 and 250,000 Thai baht per year, while $15.6 \%$ of the smart farmers lacking awareness of the AEC earned between 100,001 and 250,000 Thai baht.

We found that $19.7 \%$ of the smart farmers having knowledge about the AEC were of those who mostly attended agricultural meetings, training, or seminars; $9.0 \%$ of them definitely followed the marketing news; and $11.5 \%$ of them moderately followed marketing news. Unlike the first group, $17.2 \%$ of the smart farmers having no knowledge about the AEC followed the marketing news, $16.4 \%$ of them followed the marketing news quite little and $14.7 \%$ of them moderately followed the marketing news.

The "smart farmers" were aware of the AEC. There were only $14.8 \%$ of them asking for more knowledge about agriculture from various sources. About $13.1 \%$ of them were in the group that highly enquired for knowledge about agriculture; and $11.5 \%$ of them moderately enquired about the AEC from various sources. For the "smart farmers" having no knowledge about the AEC, approximately $47.5 \%$ of them had moderately sought knowledge about the

Table 1: The smart farmers' perceptions and awareness of the AEC, according to participation in agricultural meetings and training sessions. (Source: The 1st Office of Agriculture Economics, Chiang Mai, Thailand, 2014.)

\begin{tabular}{|c|c|c|c|c|c|c|}
\hline \multirow{2}{*}{$\begin{array}{c}\text { Participation } \\
\text { in meetings }\end{array}$} & \multicolumn{4}{|c|}{ Items } & \multicolumn{2}{c|}{ Total } \\
\cline { 2 - 7 } & \multicolumn{2}{|c|}{ Awareness } & \multicolumn{2}{c|}{ Unawareness } & \multicolumn{2}{|c|}{} \\
\cline { 2 - 7 } & Quantity & Percent & Quantity & Percent & Quantity & Percent \\
\hline High & 24 & 19.7 & - & - & 24 & 19.7 \\
Quite high & 11 & 9.0 & 14 & 11.5 & 25 & 20.5 \\
Moderate & 14 & 11.5 & 18 & 14.7 & 32 & 26.2 \\
Quite low & - & - & 20 & 16.4 & 20 & 16.4 \\
Low & - & - & 21 & 17.2 & 21 & 17.2 \\
\hline Total & 49 & 40.2 & 73 & 59.8 & 122 & 100.0 \\
\hline
\end{tabular}


Table 2: The awareness level of the "smart farmers" in the upper northern areas of Thailand about the AEC, according to the number of them enquiring about agriculture. (Source: The 1st Office of Agriculture Economics, Chiang Mai, Thailand, 2014.)!

\begin{tabular}{|c|c|c|c|c|c|c|}
\hline \multirow{2}{*}{$\begin{array}{c}\text { Knowledge } \\
\text { enquiry }\end{array}$} & \multicolumn{4}{|c|}{ Item } & \multicolumn{2}{c|}{ Total } \\
\cline { 2 - 7 } & \multicolumn{2}{|c|}{ Awareness } & \multicolumn{2}{c|}{ Unawareness } & \multicolumn{2}{c|}{} \\
\cline { 2 - 7 } & Quantity & Percent & Quantity & Percent & Quantity & Percent \\
\hline High & 16 & 13.1 & - & - & 16 & 13.1 \\
Quite high & 18 & 14.8 & 2 & 1.6 & 20 & 16.4 \\
Moderate & 14 & 11.5 & 58 & 47.5 & 72 & 59 \\
Quite low & 1 & 0.8 & 8 & 6.6 & 9 & 7.4 \\
Low & - & - & 5 & 4.1 & 5 & 4.1 \\
\hline Sum & 49 & 40.2 & 73 & 59.8 & 122 & 100.0 \\
\hline
\end{tabular}

AEC from various sources; $6.6 \%$ of them had sought quite little about the AEC from various sources; and $4.1 \%$ of them had rarely sought knowledge about the AEC from various sources

According to the finding, $15.6 \%$ of the farmers having knowledge about the AEC could mostly access agricultural information, $12.3 \%$ of them could somewhat access agricultural information, and $9.1 \%$ of them could moderately access agricultural information; while $39.3 \%$ of the farmers having no knowledge about the AEC could moderately access the information. Also, $13.9 \%$ of farmers having no knowledge of the AEC had little access to agricultural information and $6.6 \%$ had quite little access to it.

In terms of fondness and pride of doing agriculture, $33.7 \%$ of the "smart farmers" having knowledge about the AEC were highly proud and fond of doing agriculture, $4.9 \%$ of them were quite proud and fond of it, and $0.8 \%$ of them were moderately proud and fond of it. On the other hand, $45.1 \%$ of the "smart farmers" having no knowledge about the AEC were highly fond and proud of doing agriculture, $9 \%$ of them were quite proud and fond of it, and $3.3 \%$ were moderately proud and fond of it.

In terms of following marketing news, $20.5 \%$ of the "smart farmers" who were aware of the AEC were highly following marketing news, $13.1 \%$ of them somewhat followed the news and $3.3 \%$ moderately followed marketing news. Also, $18.8 \%$ of the farmers having no knowledge about the AEC followed marketing news, $18.1 \%$ somewhat followed it and $11.4 \%$ (14 samples) rarely followed marketing news.

Maximum likelihood estimation for the logit model was theoretically used to study the factors influencing the perceptions and awareness of the AEC of the "smart farmers" in the upper north of Thailand; and marginal effect was used to study the probability of the factors. Also, the estimation could be explained by the coefficients found in the estimation.

After considering the percentage of the!predictive model from the correlations of gender, participation in agricultural meetings or seminars, participation in agricultural exhibitions, agricultural knowledge enquiry from various sources, information access and the following of marketing news, the predictive value which predicted that the "smart farmers" were aware of the AEC was $63.1 \%$, while the predictive value predicting that the "smart farmers" were not aware of the AEC was $36.9 \%$; however, we found that the real value of the "smart farmers" having knowledge about the AEC was 59.8\%, while the real value of the smart 
Table 3: The smart farmers' perceptions and awareness of the AEC by following the marketing news. (Source: The 1st Office of Agriculture Economics, Chiang Mai, Thailand, 2014.)

\begin{tabular}{|c|c|c|c|c|c|c|}
\hline \multirow{2}{*}{$\begin{array}{c}\text { Following the } \\
\text { marketing } \\
\text { news }\end{array}$} & \multicolumn{4}{|c|}{\begin{tabular}{c} 
Items \\
Perceptions and \\
\cline { 2 - 7 }
\end{tabular}} & $\begin{array}{c}\text { No perception and } \\
\text { anareness }\end{array}$ & \multicolumn{2}{|c|}{ Total } \\
\cline { 2 - 7 } & Quantity & Percent & Quantity & Percent & Quantity & Percent \\
\hline High & 25 & 20.5 & 23 & 18.8 & 48 & 39.3 \\
Quite high & 16 & 13.1 & 22 & 18.1 & 38 & 31.2 \\
Moderate & 4 & 3.3 & 9 & 7.4 & 13 & 10.7 \\
Quite low & 1 & 0.8 & 5 & 4.1 & 6 & 4.9 \\
Low & 3 & 2.5 & 14 & 11.4 & 17 & 13.9 \\
\hline Total & 49 & 40.2 & 73 & 59.8 & 122 & 100.0 \\
\hline
\end{tabular}

Table 4: The results of calculation of the logit model.

\begin{tabular}{|c|c|c|}
\hline Dependent variables & Independent variables & Z-Value \\
\hline \multirow{2}{*}{$\begin{array}{c}\text { "Smart farmers"" } \\
\text { perceptions and } \\
\text { awareness of the AEC }\end{array}$} & Participation in meetings & $0.01^{* *}$ \\
\cline { 2 - 3 } & Agricultural knowledge enquiry & $0.01^{* *}$ \\
\cline { 2 - 3 } & Following marketing news! & $0.003^{* * *}$ \\
\hline
\end{tabular}

Note: ${ }^{* *}$, and ${ }^{* * *}$ indicate the 0.05 and 0.01 significance levels, respectively.

farmers lacking perceptions and awareness of the AEC was $40.2 \%$. This indicates that the predictive values were quite close to the real values. In other words, the prediction was quite accurate. !

From the correlation analysis with the logit equation, the variables to do with participation in agricultural meetings or seminars, agricultural knowledge enquiry from various sources and following the marketing news were found to be correlated with the "smart farmers" perceptions and awareness of the AEC. Changes in the agricultural meetings or seminars, and agricultural knowledge enquiry from various sources had an influence on the "smart farmers" perceptions and awareness of the AEC, and these were found to be statistically significant at the 0.05 level. In terms of following the marketing news, the news was found to have an influence on the "smart farmers" perceptions and awareness of the AEC, and it was found to be statistically significant at the 0.01 level.

From the analysis, it was found that if the "smart farmers" attend more agriculture meetings and seminars, it will increase their awareness of the AEC. On the other hand, if there are fewer of them attending agriculture meetings or seminars, it is more likely that their awareness of the AEC will also decrease.

Moreover, according to the findings, if the "smart farmers" seek more agricultural knowledge from various kinds of sources, their awareness of the AEC will probably increase; 
however, if they rarely seek and find knowledge from fewer sources, they are likely to have less knowledge about the AEC.

In addition, if the "smart farmers" increasingly follow the marketing news, their awareness of the AEC will also increase; but if they rarely follow the marketing news, their awareness of the AEC will likely decrease.

From the analysis results, the factors that were statistically significant and had an impact on the "smart farmers" perceptions and awareness of the AEC were: participation in agricultural meetings or seminars, agricultural knowledge enquiry from various sources, and the following of marketing news. Also, these factors had positive correlations with the possibility of awareness of the AEC. According to the marginal effect data, the coefficients of the factors mentioned above were $0.25,0.52$ and 0.20 , respectively.

\section{CONCLUSIONS}

In conclusion, this research analysed "smart farmer" perceptions and awareness towards the AEC in six provinces of the upper northern areas of Thailand, namely: Chiang Rai, Chiang Mai, Phayao, Lamphun, Lampang, and Mae Hong Son. The study data came from the 1st Office of Agriculture Economics, Chiang Mai, Thailand. The total sample size was 122 samples that were questionnaires by mostly males aged between 51 and 60 years old, who had graduated at least Grade 4, owned less than 10 rai and had incomes between 100,001 and 250,000 Thai baht per year.

The level of "smart farmers" that attended agricultural meetings or seminars was high (75.3\%), while the level attending fairs or other activities or exhibitions was low (31.2\%). In terms of agricultural knowledge enquiry, its level was moderate (36.1\%); while the level of accessing agricultural information was high (27.9\%). In terms of pride and fondness of doing agriculture, the level was high $(78.8 \%)$. They also gathered and joined the agricultural cooperative $(68 \%)$, but had few roles within the group or the agricultural cooperatives $(22.2 \%)$. Furthermore, the level of following up on marketing news in order to know the marketing direction was high (39.3\%). Unlike previous "smart farmers", the level of attending agricultural meetings or seminars for most of the "smart farmers" who were aware of the AEC, was high (19.7\%). Likewise, the level of their attendance to activities or exhibitions was high (20.5\%). Next, in terms of their level of knowledge enquiry from various sources: it was quite high (14.8\%). Similarly, their level of access to various sources was also high (15.6\%). Additionally, in terms of pride and fondness of doing agriculture, the level was high (33.7\%). Furthermore, 34.5\% of them gathered and joined the agricultural cooperatives, but $14.8 \%$ of them had roles in the group or agricultural cooperatives. Even so, the level of "smart farmers" following the marketing news to know the marketing trends and need was considered high $(20.5 \%)$.

In contrast, the level of attendance to agricultural meetings or seminars of the "smart farmers" who had no knowledge about the AEC, was found to be low (17.2\%); and the level of attending activities and exhibitions was low, as well (23.8\%); however, in terms of agricultural knowledge enquiry from various sources, its level was found to be moderate (24.6\%). Similarly, the level of accessing agricultural information was also found to be moderate $(15.6 \%)$.

In terms of being proud and fond of farming, we found its level was high (45.1\%). Next, in terms of gathering and joining agricultural cooperatives, $33.5 \%$ of them joined agricultural cooperatives, and only $7.4 \%$ of them had roles in the cooperatives; however, the level of following of marketing news was high (18.8\%). 
This study found that the factors influencing "smart farmers" perceptions and awareness of the AEC were: participation in agricultural meetings or seminars, agricultural knowledge enquiry from various sources, and the following of marketing-related news.

\subsection{Recommendation about the findings}

Due to having little time for the "smart farmers" to gain more knowledge and awareness about the coming AEC, the knowledge about the AEC should be distributed to them in every area, because it is the best and the cheapest way. The heads of the villages should constantly get knowledge about the AEC, so that they can pass it down to their villagers via community broadcast. Knowledge about the impacts of the AEC should be shared, so that they can prepare themselves. Moreover, the village leaders should give advice to the smart farmers about how to adjust themselves to this situation. Thus, the related organization should also announce agricultural fairs and exhibitions; or inform the "smart farmers" about the AEC through government officers, heads of villagers or heads of farmer organizations all over the area with households and sectors associated with agriculture. Or the AEC should publish printed media; such as weekly magazines, newsletters, or leaflets; or give radio shows about the AEC, and distribute or send these to every farmer in each household, so the farmers can get more information.

\subsection{Suggestions for further study}

From this study examining the correlation of factors affecting the "smart farmers"" perceptions and awareness about the ASEAN Economic Community, it appears the sample group should be increased, so that it can represent more of the population. Also, the variables or factors affecting communication must be various, as even the factor regarding working experience also has an impact on the "smart farmers" " perceptions and awareness. Therefore, for the next future study, this factor should be added to the study of the influences on "smart farmers" perceptions and awareness of the AEC.

\section{ACKNOWLEDGEMENT}

This research was financially supported by Chiang Mai University, Thailand.

\section{REFERENCES}

[1] Dungey, M., Khan, F. \& Raghavan, M., International trade and the transmission of shocks: the case of ASEAN-4 and NIE-4 economies. Economic Modelling, 72, pp. 109-121, 2018.

[2] Apiruedee, Y., The ASEAN Economic Community and agricultural labor impact. Academic Journal Review, 20(3), pp. 5-8, 2012.

[3] Wynne-Jones, S., Understanding farmer co-operation: exploring practices of social relatedness and emergent affects. Journal of Rural Studies, 53, pp. 259-226, 2017.

[4] Kanokorn, S., Vijitsri, S., Boonjit, T., Prapinwadee, S., Pornprapa, K. \& Masahiro, Y., Preparing agricultural product marketing for the new AEC market: a case study for improving the marketing organization for farmers in Chiang Rai Province, Thailand. Journal of Agricultural Extension and Rural Development, 7(4), pp. 105-113, 2015.

[5] Corry, E., O’Donnell, J., Curry, E., Coakley, D., Pauwwels, P. \& Keane, M., Using semantic web technologies to access soft AEC data. Advanced Engineering Informatics, 28(4), pp. 370-380, 2014.

[6] Nazir, A.H. \& Liljenström, H., A cortical network model of cognitive and emotional influences in human decision making. Biosystems, 136, pp. 128-141, 2015. 
[7] Zhang, Y., Zhang, Z., Liu, L. \& Shen, D., The interaction of financial news between mass media and new media: evidence from news on Chinese stock market. Physica A: Statistical Mechanics and its Applications, 486, pp. 535-541, 2017.

[8] Zahedzadeh, G., Overt attacks and covert thoughts. Aggression and Violent Behavior, 36, pp. 1-8, 2017.

[9] Kykalová, M. \& Vasilyeva, E.A., On the problem of categorizing students based on their cognitive styles and teaching strategies. Procedia - Social and Behavioral Sciences, 176(20): pp. 578-587, 2015.

[10] Hüseyin, H.ÿ., The importance of personality traits in students perceptions of metacognitive awareness. Procedia - Social and Behavioral Sciences, 232, pp. 655667, 2016.

[11] Wongchai, A., Factors affecting farmland sales in rural northern Thailand. Advanced Science Letters, 21(6), pp. 2119-2123, 2015. 